\title{
Current Opinion on Preservation of the Pylorous in Pancreato-Duodenectomy
}

\author{
Theodoros E Pavlidis ${ }^{\mathrm{a}, \mathrm{b}}$, Nikolaos G Symeonidis ${ }^{\mathrm{a}}$, Kyriakos Psarras ${ }^{\mathrm{a}}$, \\ Efstathios T Pavlidis ${ }^{\text {a }}$, Athanasios K Sakantamis ${ }^{\text {a }}$
}

\begin{abstract}
Pyloric preservation as modification to standard Whipple procedure was introduced to prevent the complications of gastrectomy ensuring better gastrointestinal function. It was initially established as the operation of choice for chronic pancreatitis but remained debatable in case of malignancy, since adenocarcinoma of the pancreas has dismal prognosis and radical resection is the only chance for cure. A PubMed search of relevant articles published up to day was performed to identify current information about pylorous preserving pancreatoduodenectomy especially its outcome regarding radicality and delayed gastric emptying. Pancreatoduodenectomy with pyloric preservation deals with better functional and nutritional outcome. It exhibits similar oncological efficacy with standard Whipple operation for the treatment of cancer of the pancreatic head and the periampullary area; it is considered as the procedure of choice in most of the cases. Delayed gastric emptying is not exclusively associated with pyloric preservation. The antecolic placement of the duodenojejunal anastomosis together with respect to the neurovascular integrity during dissection could contribute to prevention of this complication. The preservation of the stomach by resection only the pyloric ring has been proposed as a new approach. The preservation of the pylorus has already been consecrated for both
\end{abstract}

Manuscript accepted for publication April 19, 2012

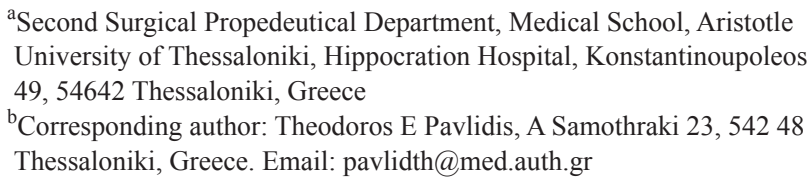

doi: $10.4021 / \mathrm{jcs} 35 \mathrm{w}$ benign and malignant disease with satisfactory short and long term results.

Keywords: Pancreatectomy; Pancreatic diseases management; Pylorus preservation; Pancreatic surgery; Whipple operation; Pancreatic cancer

\section{Historical Perspective and Operative Goals}

The modern era of pancreatic surgery essentially begins in 1935, the year that Whipple published a report presenting the first successful two-stage radical pancreatoduodenectomy for cancer of the ampulla of Vater [1]. The first stage of the operation included the construction of a gastrojejunal anastomosis, ligation of the distal common bile duct and formation of a cholecystogastric anastomosis. In the second stage, the second part of the duodenum, ampulla of Vater, pancreatic head and distal common bile duct were resected and the pancreatic remnant was oversewn. In 1941 both Whipple and Trimble independently performed the one-stage pancreatoduodenectomy with antrectomy $[2,3]$.

In 1944 Watson described for the first time pancreatoduodenectomy for carcinoma of the ampulla of Vater with preservation of the antrum, pylorus and the proximal 2.5 centimeters of the duodenum, followed by an end-to-side duodenojejunal anastomosis [4]. This operation was believed to achieve better digestion and prevention of anastomotic ulcer formation. Nevertheless, it was abandoned because of concerns regarding its radicality in case of malignancy and replaced by partial gastrectomy with or without truncal vagotomy [5].

In 1978 Traverso and Longmire reintroduced the concept of pyloric preservation in a report in which they preserved the pylorus during pancreatoduodenectomy in two patients with encouraging results [6]. They suggested that pyloric preservation prevents the complications of gastrectomy (dumping, diarrhea, anastomotic ulcer, alkaline gastritis) and ensures better gastrointestinal function. Further evidence was provided by the same authors in a subsequent study in 1980 in which 18 patients who underwent pancreatoduode- 
nectomy with pyloric preservation for chronic pancreatitis or early periampullary carcinoma were followed [7]. Their results, in accordance with other similar reports, showed that pyloric preservation provides satisfactory functional and nutritional outcome, hence improved quality of life [8]. Based on these reports, pyloric preservation was initially established as the operation of choice for chronic pancreatitis but controversy remained regarding its oncologic adequacy in case of malignancy.

\section{Operative Technique}

An important initial step of the procedure is the careful dissection of the duodenal bulb and ligation of the gastroduodenal artery $1 \mathrm{~cm}$ distal to the pylorus over the duodenum. The duodenum is resected $2-4 \mathrm{~cm}$ distal to the pylorus. It is essential that pyloric innervation and vascularization must be kept intact in order to prevent gastric dysfunction during the early postoperative period. Continuity of the gastrointestinal tract is restored with a two-layer end-to-side or end-toend duodenojejunal anastomosis depending on the preferred order of the anastomoses $[5,6,9]$. This anastomosis is constructed $40 \mathrm{~cm}$ distal to the preceding hepatojejunal anastomosis [10] and can be either retrocolic (used during the early years of the procedure) or antecolic (currently used). Many authors prefer the antecolic anastomosis because they believe it provides better gastric emptying [10-12]. Delayed gastric emptying is reported in more than $30 \%$ of the patients with retrocolic and less than $15 \%$ with antecolic anastomosis [12].

\section{Outcome}

\section{Radicality}

Pancreatic cancer exhibits an aggressive growth pattern, which is associated with discouragingly poor prognosis. Radical resection represents the only chance for cure [13-21] and the sole determinant of the outcome [22]. It has been postulated that R1 resection (positive resection margin) is associated with poorer prognosis [23]. However, in contrast to that, it has been argued that, although R2 (macroscopic residual) resection is an independent predictor of poor prognosis, R1 resection does not affect survival [24]. Undoubtedly, it should be stressed that successful curative resection with limited blood loss can contribute to improved survival [25]. Nowadays long-term survival after R0 curative surgery has become a reality [26]. It should be emphasized that the differentiation of the tumor and nodal involvement are major predictors of the outcome [23]]. Morbidity remains high; major complications include delayed gastric emptying, pancreatojejunal anastomosis leakage or pancreatic fistula, intaperitoneal abscess and haemorrhage [27].

There are also, rare reports of repeated pancreatectomy for recurrent pancreatic carcinoma after pylorus-preserving pancreatoduodenectomy which may provide a chance for long-term survival $[28,29]$.

There is currently sufficient evidence supporting that pyloric preservation demonstrates superior postoperative outcome compared to standard Whipple operation, without compromising the oncologic outcome and subsequently the survival in pancreatic cancer $[30,31]$. As a result, pyloric preservation is now widely accepted as part of the operative procedure for the treatment of chronic pancreatitis and cancer of the head of the pancreas or especially in the periampullary region. On the other hand, it seems that there is neither advantage nor disadvantage of pylorus-preserving pancreatoduodenectomy with pancreatico-jejunal anastomosis or pancreatico-gastric anastomosis [32].

Besides the advantages and disadvantages of pyloric preservation and standard Whipple procedure, they have in common two major complications, pancreatic leakage and hemorrhage. Fortunately, the substantially high operative mortality encountered in the past, which was as high as $20 \%$, is currently less than $5 \%$. The initial argument that pyloric preservation restricts the area of resection has recently been questioned. No histological evidence of tumor infiltration in the area adjacent to the pylorus and in the lymph nodes of the lesser and greater curvatures of the stomach following standard Whipple operation has been reported. Its now widely accepted that pyloric preservation is suitable for most cases of pancreatic head cancer [33]. Standard Whipple procedure should be preferred in patients with large tumors and especially when located in the superior part of the head of the pancreas [13].

Various retrospective studies showed that pyloric preservation was superior to standard Whipple procedure in terms of gastrointestinal function and quality of life, but no significant difference was found in survival by other studies either retrospective or prospective randomized [13]. Pyloric preservation is safe and radical for the treatment of cancer of the head of the pancreas and the periampullary area, with similar survival, local reccurrence and distant metastasis rates when compared to standard Whipple procedure [34].

\section{Delayed gastric emptying}

In 1985 Warshaw described for the first time delayed gastric emptying which was found in $25 \%$ of the cases and was initially attributed to pyloric preservation [35]. Subsequent studies showed that delayed gastric emptying is equally presented in the postoperative period following standard Whipple procedure $[13,33,36]$.

Transient gastric stasis impairing normal gastric function is common following pancreatoduodenectomy and usually resolves within 2 - 4 weeks. In the meantime, prolonged 
nasogastric tube suction and hospital stay are required. This temporary gastric dysfunction during the early postoperative period can be attributed to either anastomotic edema or damage to the neurovascular supply. The hypothesis that neural and vascular integrity prevents delayed gastric emptying is supported by the fact that this complication occurs in $8 \%$ after pyloric preservation and $40 \%$ after standard Whipple operation [33]. Subsequently, there is no clear evidence to suggest that pyloric preservation is to blame for delayed gastric emptying. This complication probably results from other postoperative sequelae as angulation of the duodenojejunal anastomosis, subclinical leakage from the pancreatojejunal anastomosis and transient postoperative pancreatitis. It occurred in $12 \%$ of the patients following pyloric preservation and $21 \%$ following standard Whipple operation [11].

Various prospective randomized controlled studies investigated delayed gastric emptying, quality of life and longterm survival following pancreatoduodenectomy. A study from Japan showed that antecolic placement of the duodenojejunal anastomosis in pyloric preservation results in delayed gastric emptying in $5 \%$ of the cases, which is significantly lower than the $50 \%$ found when the anastomosis was constructed in a retrocolic fashion [13]. However, a recent randomized controlled trial found that the incidence of delayed gastric emptying appear to be unrelated to the method of reconstruction, either this is antecolic (34.4\%) or retrocolic (27.8\%). Older age may be a risk factor [37]. Pathogenesis of this complication includes various predisposing factors such as local ischemia of the antrum, deprivation of duodenal motilin, postvagotomy gastric atony and gastric dysfunction related to other complications (e.g. abscess).

In a study from Germany, pyloric preservation as part of an operation for pancreatic cancer was found to achieve superior results compared to standard Whipple in terms of duration of the operation, intraoperative blood loss, delayed gastric emptying, hospital stay. Long-term outcome such as gastrointestinal function and digestion were also found superior but morbidity ( $30 \%$ vs. $32 \%)$, mortality ( $5 \%$ vs. $3 \%$ ) and mean survival did not differ significantly [10].

A multi-center, prospective, randomized study from Holland involving 170 patients with cancer of the pancreas and the periampullary area, showed no difference between pyloric preservation and standard Whipple in terms of operative blood loss, duration of the operation, hospital stay, delayed gastric emptying, morbidity and mortality. Mean survival and disease-free survival also showed no significant difference. Therefore, both techniques are considered by the authors as equally effective for the treatment of periampullary cancer [38]. However, in a recent prospective, randomized, controlled trial, resection of the pyloric ring with preservation of nearly the entire stomach was found to result in significantly lower incidence of delayed gastric emptying $(4.5 \%)$ compared to pylorus-preserving pancreatoduodenectomy $(17.2 \%)$ [39].
Limited data and only in selected patients exist concerning the laparoscopic approach [40] or robotic-assisted major pancreatic resection [41].

\section{Conclusions}

Pancreatoduodenectomy with pyloric preservation demonstrates acceptable functional and nutritional outcome with the additional benefit of preventing the complications of gastrectomy. It exhibits similar oncological efficacy with standard Whipple operation for the treatment of cancer of the pancreatic head and the periampullary area and is considered as the procedure of choice in most of the cases. Delayed gastric emptying is not exclusively associated with pyloric preservation and antecolic placement of the duodenojejunal anastomosis together with respect to the neurovascular integrity during dissection could contribute to prevention of this complication.

\section{Funding}

None.

\section{Ethical Approval}

Not needed.

\section{Contributors}

PTE wrote the main body of the article with the help of SNG, PET and PK under the supervision of SAK. PET provided advice on literature data and their interpretation, while SAK provided advice on surgical aspects. PTE is the guarantor.

\section{Competing Interest}

No benefits in any form have been received or will be received from a commercial party related directly or indirectly to the subject of this article.

\section{References}

1. Whipple AO, Parsons WB, Mullins CR. Treatment of Carcinoma of the Ampulla of Vater. Ann Surg. 1935;102(4):763-779.

2. Whipple AO. The Rationale of Radical Surgery for Cancer of the Pancreas and Ampullary Region. Ann Surg. 1941;114(4):612-615. 
3. Trimble IR, Parsons JW, Sherman CP. A one-stage operation for the cure of carcinoma of the ampulla of Vater and the head of the pancreas. Surg Gynecol Obstet 1941; 73: 711-722.

4. Watson K. Carcinoma of the ampulla of Vater. Successful radical resection. Br J Surg 1944; 31: 368-373.

5. Grace PA, Pitt HA, Longmire WP. Pylorus preserving pancreatoduodenectomy: an overview. Br J Surg. 1990;77(9):968-974.

6. Traverso LW, Longmire WP, Jr. Preservation of the pylorus in pancreaticoduodenectomy. Surg Gynecol Obstet. 1978;146(6):959-962.

7. Traverso LW, Longmire WP, Jr. Preservation of the pylorus in pancreaticoduodenectomy a follow-up evaluation. Ann Surg. 1980;192(3):306-310.

8. Hunt DR, McLean R. Pylorus-preserving pancreatectomy: functional results. Br J Surg. 1989;76(2):173-176.

9. Wagner M, Z'Graggen K, Vagianos CE, Redaelli CA, Holzinger F, Sadowski C, Kulli C, et al. Pylorus-preserving total pancreatectomy. Early and late results. Dig Surg. 2001;18(3):188-195.

10. Niedergethmann M, Shang E, Farag Soliman M, Saar J, Berisha S, Willeke F, Post S. Early and enduring nutritional and functional results of pylorus preservation vs classic Whipple procedure for pancreatic cancer. Langenbecks Arch Surg. 2006;391(3):195-202.

11. Horstmann O, Markus PM, Ghadimi MB, Becker H. Pylorus preservation has no impact on delayed gastric emptying after pancreatic head resection. Pancreas. 2004;28(1):69-74.

12. Tani M, Terasawa H, Kawai M, Ina S, Hirono S, Uchiyama K, Yamaue H. Improvement of delayed gastric emptying in pylorus-preserving pancreaticoduodenectomy: results of a prospective, randomized, controlled trial. Ann Surg. 2006;243(3):316-320.

13. Bachmann J, Michalski CW, Martignoni ME, Buchler MW, Friess H. Pancreatic resection for pancreatic cancer. HPB (Oxford). 2006;8(5):346-351.

14. Baumel H, Huguier M, Manderscheid JC, Fabre JM, Houry S, Fagot H. Results of resection for cancer of the exocrine pancreas: a study from the French Association of Surgery. Br J Surg. 1994;81(1):102-107.

15. Bramhall SR, Allum WH, Jones AG, Allwood A, Cummins C, Neoptolemos JP. Treatment and survival in 13,560 patients with pancreatic cancer, and incidence of the disease, in the West Midlands: an epidemiological study. Br J Surg. 1995;82(1):111-115.

16. Zerbi A, Balzano G, Patuzzo R, Calori G, Braga M, Di Carlo V. Comparison between pylorus-preserving and Whipple pancreatoduodenectomy. Br J Surg. 1995;82(7):975-979.

17. Shah OJ, Robbani I, Nazir P, Khan AB. Central pancreatectomy: a new technique for resection of selected pancreatic tumors. Hepatobiliary Pancreat Dis Int.
2009;8(1):93-96.

18. Koliopanos A, Avgerinos C, Farfaras A, Manes C, Dervenis C. Radical resection of pancreatic cancer. Hepatobiliary Pancreat Dis Int. 2008;7(1):11-18.

19. Zhou GW, Wu WD, Xiao WD, Li HW, Peng CH. Pancreatectomy combined with superior mesenteric-portal vein resection: report of 32 cases. Hepatobiliary Pancreat Dis Int. 2005;4(1):130-134.

20. Zhou J, Li CL, Zhang GW. Surgical treatment of pancreatic carcinoma. Hepatobiliary Pancreat Dis Int. 2003;2(1):139-141.

21. Ni QX, Zhang QH, Fu DL, Cao GH, Yao QY, Jin C, Yu $\mathrm{XJ}$, et al. Curative resection of pancreatic head carcinoma in recent 30 years: report of 377 cases. Hepatobiliary Pancreat Dis Int. 2002;1(1):126-128.

22. Wagner M, Redaelli C, Lietz M, Seiler CA, Friess H, Buchler MW. Curative resection is the single most important factor determining outcome in patients with pancreatic adenocarcinoma. Br J Surg. 2004;91(5):586-594.

23. Badger SA, Brant JL, Jones C, McClements J, Loughrey MB, Taylor MA, Diamond T, et al. The role of surgery for pancreatic cancer: a 12-year review of patient outcome. Ulster Med J. 2010;79(2):70-75.

24. Kato K, Yamada S, Sugimoto H, Kanazumi N, Nomoto S, Takeda S, Kodera Y, et al. Prognostic factors for survival after extended pancreatectomy for pancreatic head cancer: influence of resection margin status on survival. Pancreas. 2009;38(6):605-612.

25. Nagai S, Fujii T, Kodera Y, Kanda M, Sahin TT, Kanzaki A, Yamada S, et al. Impact of operative blood loss on survival in invasive ductal adenocarcinoma of the pancreas. Pancreas. 2011;40(1):3-9.

26. Adham M, Jaeck D, Le Borgne J, Oussoultzouglou E, Chenard-Neu MP, Mosnier JF, Scoazec JY, et al. Longterm survival (5-20 years) after pancreatectomy for pancreatic ductal adenocarcinoma: a series of 30 patients collected from 3 institutions. Pancreas. 2008;37(4):352357.

27. Spanknebel K, Conlon KC. Advances in the surgical management of pancreatic cancer. Cancer J. 2001;7(4):312-323.

28. Ogino T, Ueda J, Sato N, Takahata S, Mizumoto K, Nakamura M, Oda Y, et al. Repeated Pancreatectomy for Recurrent Pancreatic Carcinoma after Pylorus-Preserving Pancreatoduodenectomy: Report of Two Patients. Case Rep Gastroenterol. 2010;4(3):429-434.

29. Koizumi M, Sata N, Kasahara N, Morishima K, Sasanuma H, Sakuma Y, Shimizu A, et al. Remnant pancreatectomy for recurrent or metachronous pancreatic carcinoma detected by FDG-PET: two case reports. JOP. 2010;11(1):36-40.

30. Ozawa F, Friess H, Kunzli B, Shrikhande SV, Otani T, Makuuchi M, Buchler MW. Treatment of pancreatic cancer: the role of surgery. Dig Dis. 2001;19(1):47-56. 
31. Glanemann M, Bahra M, Neuhaus P. [Pylorus-preserving pancreatic head resection: a new standard for tumors]. Chirurg. 2008;79(12):1107-1114.

32. Huguier M, Barrier A, Gouillat C, Suc B, Jaeck D, Launois B. [Pancreaticoduodenectomy for cancer of the head of the pancreas]. J Chir (Paris). 2008;145(1):9-15.

33. Liu SL, Friess H, Kleeff J, Ji ZL, Buchler MW. Surgical approaches for resection of pancreatic cancer: an overview. Hepatobiliary Pancreat Dis Int. 2002;1(1):118-125.

34. Klinkenbijl JH, van der Schelling GP, Hop WC, van Pel $\mathrm{R}$, Bruining HA, Jeekel J. The advantages of pyloruspreserving pancreatoduodenectomy in malignant disease of the pancreas and periampullary region. Ann Surg. 1992;216(2):142-145.

35. Warshaw AL, Torchiana DL. Delayed gastric emptying after pylorus-preserving pancreaticoduodenectomy. Surg Gynecol Obstet. 1985;160(1):1-4.

36. Paraskevas KI, Avgerinos C, Manes C, Lytras D, Dervenis C. Delayed gastric emptying is associated with pylorus-preserving but not classical Whipple pancreaticoduodenectomy: a review of the literature and critical reappraisal of the implicated pathomechanism. World $\mathrm{J}$ Gastroenterol. 2006;12(37):5951-5958.

37. Gangavatiker R, Pal S, Javed A, Dash NR, Sahni P,
Chattopadhyay TK. Effect of antecolic or retrocolic reconstruction of the gastro/duodenojejunostomy on delayed gastric emptying after pancreaticoduodenectomy: a randomized controlled trial. J Gastrointest Surg. 2011;15(5):843-852.

38. Tran KT, Smeenk HG, van Eijck CH, Kazemier G, Hop WC, Greve JW, Terpstra OT, et al. Pylorus preserving pancreaticoduodenectomy versus standard Whipple procedure: a prospective, randomized, multicenter analysis of 170 patients with pancreatic and periampullary tumors. Ann Surg. 2004;240(5):738-745.

39. Kawai M, Tani M, Hirono S, Miyazawa M, Shimizu A, Uchiyama K, Yamaue H. Pylorus ring resection reduces delayed gastric emptying in patients undergoing pancreatoduodenectomy: a prospective, randomized, controlled trial of pylorus-resecting versus pylorus-preserving pancreatoduodenectomy. Ann Surg. 2011;253(3):495-501.

40. Rosok BI, Marangos IP, Kazaryan AM, Rosseland AR, Buanes T, Mathisen O, Edwin B. Single-centre experience of laparoscopic pancreatic surgery. Br J Surg. 2010;97(6):902-909.

41. Zureikat AH, Nguyen KT, Bartlett DL, Zeh HJ, Moser AJ. Robotic-assisted major pancreatic resection and reconstruction. Arch Surg. 2011;146(3):256-261. 